\title{
BMJ Open Understanding the motivation and performance of community health volunteers involved in the delivery of health programmes in Kampala, Uganda: a realist evaluation protocol
}

\author{
Gaëlle Vareilles,, ${ }^{1,2}$ Jeanine Pommier, ${ }^{1,2}$ Sumit Kane, ${ }^{3}$ Gabriel Pictet, ${ }^{4}$ \\ Bruno Marchal $^{5}$
}

To cite: Vareilles G,

Pommier J, Kane S, et al. Understanding the motivation and performance of community health volunteers involved in the delivery of health programmes in Kampala, Uganda: a realist evaluation protocol. BMJ Open 2015:5:e06752. doi:10.1136/bmjopen-2014006752

- Prepublication history and additional material is available. To view please visit the journal (http://dx.doi.org/ 10.1136/bmjopen-2014006752)

Received 28 September 2014 Revised 1 December 2014 Accepted 3 December 2014

CrossMark

For numbered affiliations see end of article.

Correspondence to Dr Gaëlle Vareilles Vareilles.gaelle@gmail.com

\section{ABSTRACT}

Introduction: The recruitment of community health volunteers to support the delivery of health programmes is a well-established approach in many countries, particularly where health services are not readily available. However, studies on management of volunteers are scarce and current research on human resource management of volunteers faces methodological challenges. This paper presents the protocol of a realist evaluation that aims at identifying the factors influencing the performance of community health volunteers involved in the delivery of a Red Cross immunisation programme in Kampala (Uganda) with a specific focus on motivation.

Methods and analysis: The realist evaluation cycle structures the protocol. To develop the theoretical basis for the evaluation, the authors conducted interviews and reviewed the literature on community health volunteers' performance, management and organisational behaviour. This led to the formulation of the initial programme theory, which links the intervention inputs (capacitybuilding strategies) to the expected outcomes (positive work behaviour) with mechanisms that point in the direction of drivers of motivation. The contextual elements include components such as organisational culture, resource availability, etc. A case study design will be adopted. We define a case as a Red Cross branch, run by a programme manager, and will select two cases at the district level in Kampala. Mixed methods will be used in data collection, including individual interviews of volunteers, participant observation and document review. The thematic analysis will be based on the initial programme theory and will seek for context-mechanismoutcome configurations. Findings from the two cases will be compared.

Discussion: We discuss the scope for applying realist evaluation and the methodological challenges we encountered in developing this protocol.

Ethics and dissemination: The study was approved by the Ethical Committee at Rennes University Hospital, France. Results will be published in scientific journals, and communicated to respondents and relevant institutions
Strengths and limitations of this study

To the best of our knowledge, this is the first published application of realist evaluation concerning motivation and management of community health volunteers.

- Limited guidance on how to develop a realist study meant that formulating the initial programme theory required a long lead-in time.

- Within the field of realist evaluation, there are diverging views regarding mechanisms and context conditions, and how these can be identified.

\section{INTRODUCTION}

Interventions to optimise the role of nontraditional health workers in developing countries aim to bridge the gap between communities, caregivers and the formal health system. Since the Primary Health Care approach was defined at the Alma Ata conference in 1978, voluntary health workers or community health workers have been identified as the third workforce within the 'Human resources for Health'. ${ }^{1}$ Their recruitment and involvement is now an established approach, particularly where health services are not readily available ${ }^{2}$ and several Asian and African countries are currently investing in this third workforce as a major element of their strategies to reach the Millennium Development Goals. ${ }^{3}$

There is some evidence that community health volunteers-defined as lay persons who provide health services within a formal structure on a voluntary basis (ie, free of formal obligations and without being remunerated)-can make a difference to the health and well-being of underserved communities. Some systematic reviews of the 
effectiveness of community health services delivered by non-traditional health workers show that integration of community health volunteers can lead to significant benefits for maternal and child health, the management of infectious diseases and in increasing immunisation uptake. $^{4-7}$ Other studies question the effectiveness of strategies that deploy community health volunteers to improve community health outcomes and indicate that community-based interventions involving non-paid community members, such as community health volunteers, do not consistently provide services that have substantial impact on health nor demonstrate change in the general population. Moreover, the quality of services they provide is challenged. ${ }^{8-11}$

Furthermore, low performance and high attrition rates have been reported in many community-based health programmes, with higher attrition rates associated with non-paid community health workers, such as community health volunteers. ${ }^{12-14}$ Indeed, the sustainability of the programmes is threatened by both low performance and high attrition rates.

Expanding our knowledge on what works to improve community health volunteer performance and retention is a critical issue in attempts to improve the health outcomes of underserved populations. Little is known about the reasons behind successes and failures of interventions involving community health volunteers. ${ }^{4} \quad 6 \quad 15$ Several studies identified the need for further research mainly in the following areas: the impact of local implementation of the strategy (including issues such as the type of role played by volunteers, the age and time commitment of volunteers, and how well the volunteers are trained, managed and supported) and the influence of local conditions. More specifically, authors reported the need for further research on volunteers' intentions and how or why people become and stay a volunteer. ${ }^{16}$ Indeed, we know relatively little about how volunteers perceive job satisfaction, about their long-term engagement and about how this can be improved. ${ }^{17}$

There are evidence gaps on what kind of management intervention works for two main reasons. First, the existing studies on management of volunteers are scarce. In part, we suspect this is due to the fact that many of the concepts, theories and measures of work and organisational psychology are built on the premise of paid work, while much of the existing research on volunteering has largely ignored work and organisational psychology. ${ }^{18}$ Furthermore, many experiences with community health volunteer programmes in the developing world are not appropriately documented or not documented at all. ${ }^{2} 4$ Assessing volunteer performance, measuring attrition and identifying its determinants are often ignored in favour of reporting effects on health outcomes. ${ }^{13}$ Second, the scholarship in the field of human resources management consistently refers to the failure of researchers to fully embrace the complexity of human behaviour in health organisations ${ }^{19-21}$ and the methodological challenges involved in doing so. Community health volunteer interventions are complex interventions, embedded within multifaceted health and social systems, and the success of such interventions is highly context dependent. This not only raises questions about the applicability of study results to different settings, but it also requires using appropriate study designs and methodologies to answer the unanswered questions adequately. ${ }^{22} 23$

Within this panorama, the Red Cross Red Crescent (RC) National Societies implement capacity-building programmes that are based on training, supervision and support, and seek to develop a pool of capable volunteers with the aim of improving the health of underserved communities. This study intends to address the evidence gap on volunteer management by focusing on volunteer motivation. Researching the involvement of RC volunteers in community-based health activities, we will inquire about the motivation that drives RC community health volunteers to seek out opportunities, to commit themselves to community-based health activities, and to sustain their involvement over extended periods in the RC National Society to which they belong.

We present in this paper the protocol of an evaluation of the capacity-building component of the RC Community-Based Health Immunisation Programme at the district level in Kampala, the capital of Uganda. The capacity-building intervention consists of training, supervision and support. It aims to develop a network of competent volunteers at the district level for strengthening routine immunisation activities. The background of the study is presented first, followed by a discussion of the approach, design and methods we plan to use. Finally, the paper ends with a discussion of methodological issues of the protocol.

\section{BACKGROUND}

National Red Cross Red Crescent Societies, among them the Uganda Red Cross Society, want to improve the performance of their volunteers to deliver effective health services to underserved communities. As the National Societies experience difficulties in motivating and retaining their volunteers, the Health and Volunteering Departments of the International Federation of Red Cross and Red Crescent Societies (IFRC) are in the process of developing a research programme to better understand how volunteer motivation can be enhanced by appropriate managerial strategies. Indeed, the role of the IFRC is to promote humanitarian principles and values, and to provide technical support and recommend management systems to member National Societies. The IFRC comprises 189 member Red Cross and Red Crescent National Societies, a global secretariat in Geneva and more than 60 delegations strategically located to support activities around the world.

This research on volunteers will contribute to the development of the $2020 \mathrm{RC}$ global framework for community health. The IFRC is reviewing its community 
health approach to address health issues for the next 30 years (eg, ageing, prevention of non-communicable diseases, home management of chronic conditions, mental health) through integrated volunteer-based community approaches (IFRC, Community-based Health and First Aid (CBHFA+) 2015-2020, Discussion Paper 2014). The new framework will be informed by a multicase study of RC Community Based Health (CBH) projects worldwide using the realist approach. The study presented in this paper is the first case study.

The choice of the methodological approach for IFRC research was shared with Red Cross Red Crescent National Societies at global and regional IFRC health meetings in 2013 and 2014. Traditional evaluations of RC National Societies' programmes are based on the summative evaluation approach that focuses on programme implementation effectiveness and relevance. Although these evaluations are very useful, many National Societies consider that clear answers on how to manage volunteer-based interventions in their specific contexts are lacking. We therefore discussed how the realist approach, by taking into consideration the local context, could explain how context-specific strategies enhance the motivation and the performance of community volunteers. Based on these discussions, National Societies submitted their CBHFA projects for study to the IFRC Health Department who, after discussion with the CBHFA programme officers, selected the Uganda RC project in Kampala as the first study. The Uganda team was the most motivated to participate in the research and already had data collected for this CBHFA programme, such as indicators on volunteer performance.

\section{The objectives}

The Red Cross Society of Uganda is implementing a CBHFA in Action programme in Kampala that includes supporting immunisation activities. The aim of the study is to understand how the motivation of the RC volunteers evolves and what RC managers can do to maintain volunteers within the $\mathrm{CBH}$ programme.

The specific objectives of the evaluation are to:

- Describe the management and leadership practices at RC branch level (district level), framed against the organisational context;

- Assess the link between management and leadership practices and the organisational context on one hand and work attitudes and work behaviour of the volunteers on the other;

- Describe the plausible mechanisms of change that explain the above linkage (or lack thereof).

\section{The setting}

Uganda remains one of the world's most impoverished countries and healthcare performance is still ranked as one of the worst in the world ${ }^{24}$ despite the recent rapid economic expansion. Uganda is also one of Africa's most rapidly urbanising countries, with a population estimated to be above 37 million. ${ }^{25}$ Almost 50 per cent of the population is below 15 years of age $e^{26}$ and it is soon expected to be one of the most densely populated countries in the world. ${ }^{27}$ The high rate of urban growth has had consequences in terms of creating unhealthy environments, ill health and social distress in the cities. In 2011, the population of Kampala was estimated to be $1659600^{28}$ and Action Aid International estimates that over one million people in Kampala live in slums. ${ }^{29}$ People living in slums are poor, hardly meet their basic needs and often lack toilets or latrines, making slums worse than rural areas. In 2013, Dr Ondoa, the Uganda Health Minister, listed urban areas, including Kampala, as some of the areas with the highest proportion of unimmunised children. ${ }^{30}$

\section{The intervention}

The Ugandan Government considers immunisation interventions as the main strategy to increase immunisation coverage and achieve the Millennium Development Goal of reducing the under 5-year-olds mortality rates by $2015 .{ }^{31}$ The government of Uganda has developed a comprehensive plan to achieve and sustain a high level of immunisation in the country, with a specific focus on underperforming districts and subdistricts, through the Reach Every District (RED) strategy.

The Uganda Red Cross Society intervenes as an auxiliary to government services through its network of volunteers, and it contributes to strengthening routine immunisation in nine selected underperforming districts, including five in Kampala. The goal of the RC project is to reduce the number of underimmunised or unimmunised children and to control measles and other vaccine-preventable diseases. Financially supported by the American Red Cross and technically supported by UNICEF and governmental agencies, the RC programme consists of providing communication and social mobilisation support and has been implemented three times up to January 2014. The main role of RC volunteers is to carry out house-to-house sensitisation, organise orientation meetings with community members, and provide a link between the health facilities that provide immunisation services and the community.

In each district, one RC programme manager and one team of volunteers are responsible for programme coordination and implementation (see figure 1 for structure of the Uganda Red Cross governance and management at national, branch and community level). Indeed, within the Uganda RC, the branches constitute management as well as governance structures, usually created to operate around established governmental district structures. The branch is generally responsible for coordinating, monitoring and documenting all activities taking place at district level. There is usually one staff member per branch acting as the programme manager. For each specific activity or programme, the volunteers are recruited by the programme manager from the RC pool 
Figure 1 Schematic showing the Uganda Red Cross Society governance and management structure at national, branch and community level.
Structure of the Uganda Red Cross Society : governance and management at national, district and community level

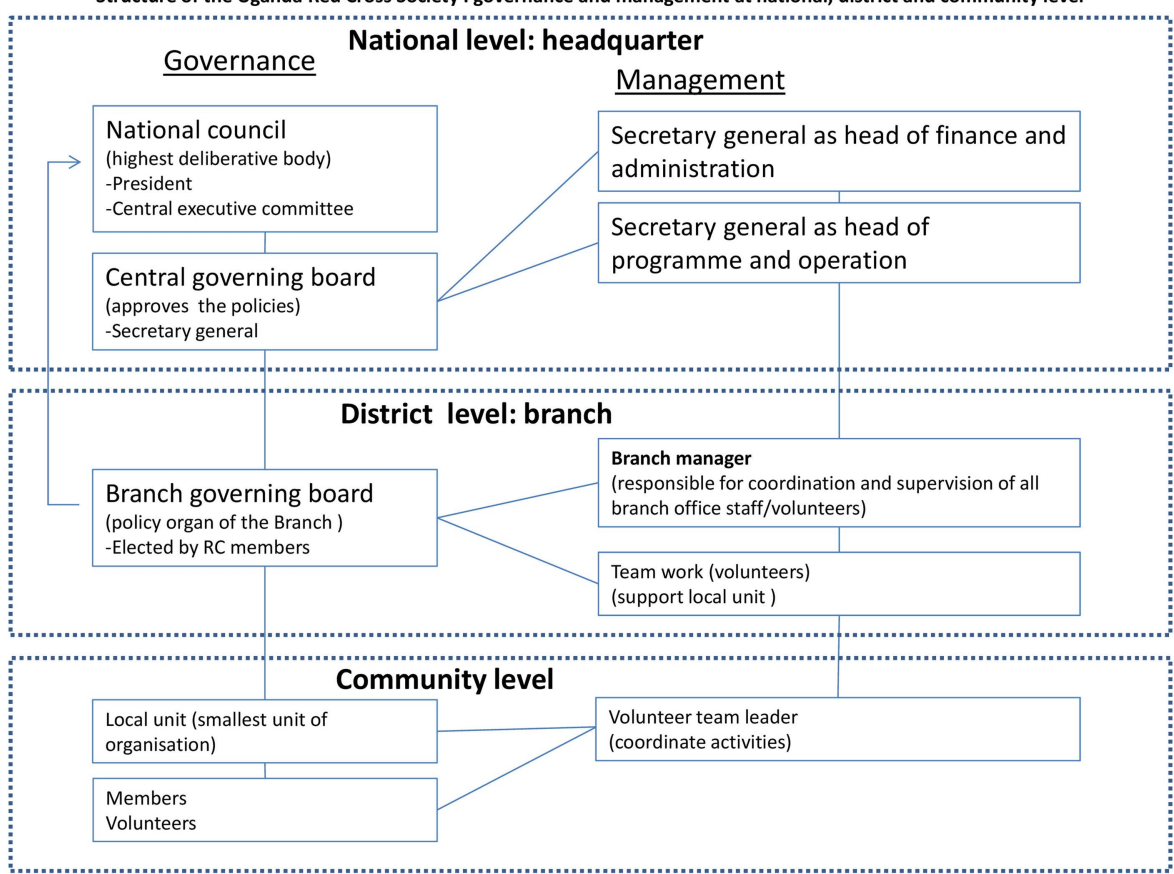

of active volunteers. For the immunisation programme, they are trained by staff from the RC and UNICEF, receive ongoing supervision from the $\mathrm{RC}$ programme manager and are paid a small allowance to cover the costs related to their involvement. The training: provides relevant technical information related to immunisation; strengthens skills; and introduces tools to mobilise the community and to address negative attitudes towards immunisation services, and more generally to tackle poor health-seeking behaviour.

\section{METHODS}

The methodological approach

The realist evaluation approach is used in this study. Reasons for choosing realist evaluation are explained in this section, together with an introduction to the approach and the stages of a realist evaluation study.

Human Resource Management interventions are complex; their outcomes are usually the result of the non-linear interaction between several actors and are highly context dependent. The RC CBH capacitybuilding intervention has all the features of a complex intervention according to the guidelines of the UK Medical Research Council for research of complex interventions, ${ }^{32}$ such as involvement of multiple stakeholders, complex tasks required by those delivering the intervention, and multiple and variable outcomes. Furthermore, the intervention contains other key features of complex intervention identified as critical by Roger, ${ }^{33}$ Pawson et $a l^{34}$ and others ${ }^{35}$ : feedback loops and constant adaptation to the local context are likely to lead to emergent behaviour and outcomes as the intervention is being implemented. In general, there is a growing consensus that research on interventions that occur in complex social systems presents significant methodological challenges and that realist evaluation provides a methodological approach to tackle many of these challenges. 33 37-40

Realist evaluation is an approach that belongs to the school of theory-driven inquiry. Researchers have been using theory-driven inquiry approaches in response to calls for better methods to deal with complexity. ${ }^{41}$ Pawson and Tilley $^{42}$ developed the realist evaluation approach arguing that in order to be useful for decisionmakers, evaluations need to indicate "what works in which conditions for whom", rather than merely "does it work?". ${ }^{43}$ In order to answer these questions, realist evaluators aim at identifying the underlying mechanisms of change that explain how an intervention reaches its outcomes.

Realist evaluation differs from other theory-driven evaluation because of its explicit philosophical foundations. It has roots in realism, adopting a position between the extremes of positivism and relativism, ${ }^{44}$ and presents a distinctive viewpoint on how interventions bring about change. It accepts that there is a reality independent of the researcher (natural realist ontology), but that knowing this reality through science is, unavoidably, relative to the researcher (weak relativist epistemology). The realist perspective on causality stresses the importance of interactions and context, on which there is a far less important focus in the other schools.

Owing to its philosophical underpinnings, realist evaluation is an appropriate approach for studying complex interventions. ${ }^{45}$ Indeed, realists understand the social world as a complex open system and recognise the importance of social relationships. They aim at identifying the generative mechanisms that underlie the social reality. Causality is here considered generative: the 
observed outcomes are produced when the intervention triggers the mechanisms, which are not directly observable, in the presence of the 'right' context factors. As a result, it may be possible to observe patterns of behaviour (demi-regularities) ${ }^{43}$ According to realist evaluation, interventions are not directly responsible for outcomes. Rather, they trigger 'mechanisms', ${ }^{46-48}$ which fire in some contexts for some people, but not in others.

Realist evaluation offers a methodological tool to search for such patterns in the form of the context-mechanism-outcome (CMO) configuration. $^{49}$ Programmes work (ie, they have good outcomes) only if they introduce the appropriate ideas and opportunities (mechanisms) to actors in the appropriate social and cultural conditions (context). By developing programme theories (PTs) that spell out such hypotheses and testing them in empirical research, it is possible to generate internally consistent and externally valid knowledge of how interventions work in a given context to produce particular outcomes.

A realist evaluation starts and ends with a theory. This theory is not grand theory, but middle range theory (MRT). While the terms 'middle range theory' and 'programme theory' are increasingly used interchangeably, one could say that the PT is all about the hypothesis underlying the intervention in question (in this case the management of community health volunteers), which presents the mechanisms through which the outcomes are expected to be brought about as well as the required context conditions. Therefore, the PT represents a hypothesis that can be tested and further developed.
The end result of a realist evaluation is a refined set of assumptions-a refined PT-that provides information on what kind of interventions work for whom, in which condition and how. The MRT operates at a slightly higher level of abstraction. MRTs can often be gleaned from other disciplines (in this case management or motivation theories), but can also be the end result of a series of realist studies. These are theories in between grand universal theories and the more specific PT that explains the results of a particular programme.

In order to understand how the Red Cross management strategies produce a change (or not) in Red Cross volunteer behaviour, we will carry out this study following the realist evaluation approach according to the cycle presented in figure 2, adapted from Pawson and Tilley $^{42}$ and Marchal et al. ${ }^{50}$ We structured the development of the study protocol following this cycle.

\section{Step 1: Formulating the PT}

Details on the concepts mentioned in this section for building the initial PT can be found in Annex 1.

To formulate the PT, realist researchers first describe the designers' and other stakeholders' assumptions, around which the programme was planned, and which explain why the programme would reach its goals. Second, the existing knowledge and evidence concerning this kind of programme are examined. Often, insights from other disciplines (in the form of MRT) can enrich the initial PT, especially with regard to the mechanisms. As we will show below, we mainly searched for useful MRTs in the psychology literature. The end

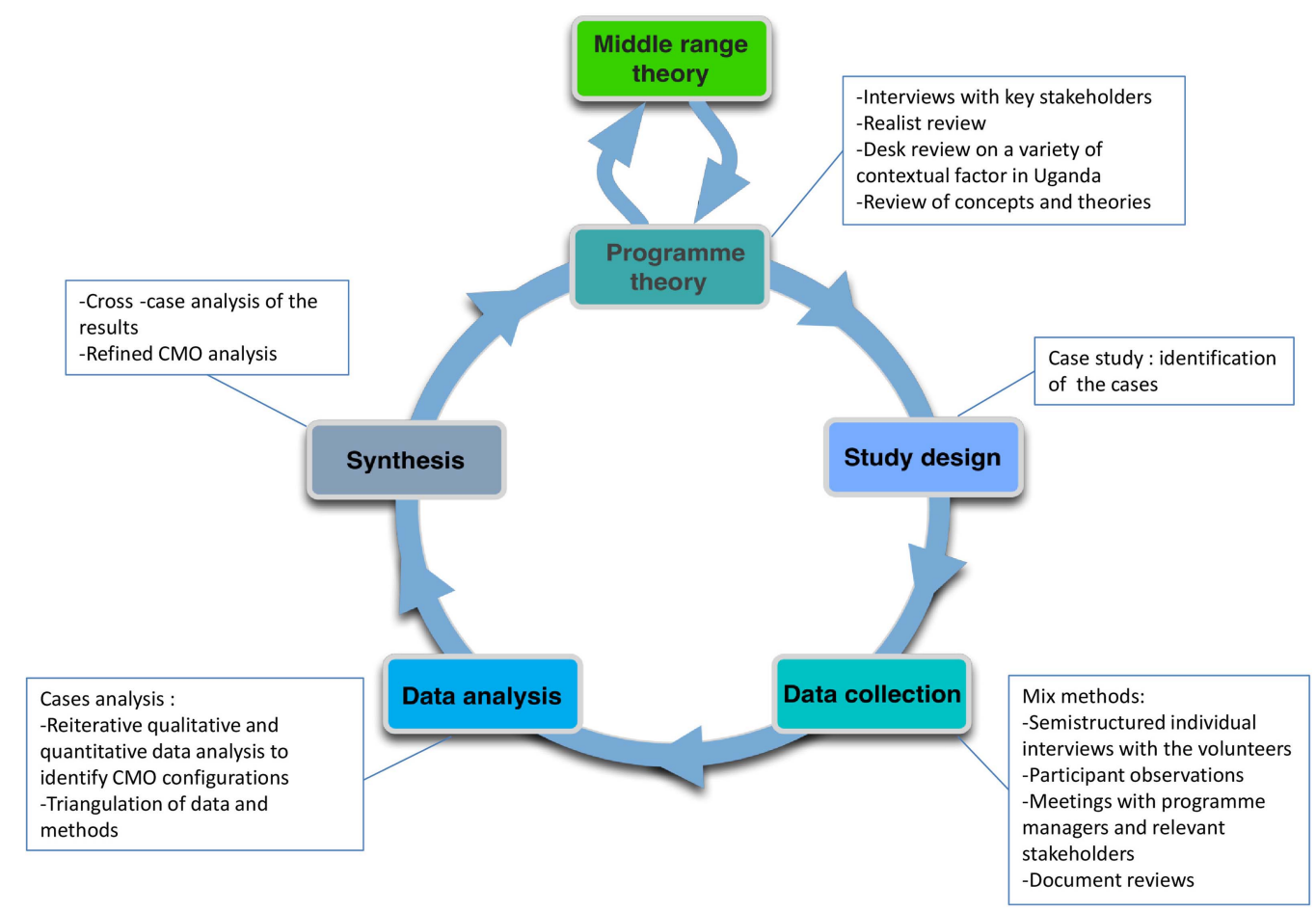

Figure 2 The Realist Evaluation cycle used in this study (adapted from Pawson and Tilley ${ }^{42}$ and Marchal et $a{ }^{36}$; CMO, context-mechanism-outcome). 
result of this step is the PT that will be the starting point, the hypothesis, that is tested in the empirical studies. In realist evaluation, all other design choices follow from the initial PT.

We therefore describe how the initial PT of the intervention was built.

Since the $\mathrm{RC}$ has $\mathrm{CBH}$ programmes in numerous countries, we first familiarised ourselves with the range of actual field activities by carrying out 20 interviews of $\mathrm{RC}$ volunteers and programme managers working in Sierra Leone, Burundi, the Philippines and Argentina. These interviews aimed at eliciting their assumptions regarding the $\mathrm{CBH}$ programme. We also interviewed experts on volunteering at the IFRC headquarters in Geneva. Second, we carried out a realist review of the literature on community health volunteer performance in $\mathrm{CBH}$ programmes to assess the existing evidence base. Third, to understand the contextual elements of our initial assumptions, we carried out an additional literature review to assess the current general context of Uganda, held conversations with Ugandan RC volunteers via Facebook, and carried out short preliminary surveys of Uganda RC staff. To structure these first inputs, we developed a realist analysis grid that we used to start mapping candidate $\mathrm{CMO}$ configurations.

Another major source of inputs into the initial PT were the literature reviews. We were searching for theories and evidence that could explain community health volunteer performance and for theories on volunteer motivation and work behaviour in non-profit organisations. A summary of the selected theories is shown in table 1 below. Through discussion among our team of researchers, with staff of the RC (and of other public organisations) who are responsible for capacity-building and strengthening in developing countries, and with experts in occupational psychology, we decided to focus mainly on self-determination theory (SDT), which we used as our main MRT. SDT represents a broad framework for the study of human motivation and allows for the assessment of level as well as quality of motivation. ${ }^{51}$ The main concepts of SDT are described in Annex 1, table 1.

SDT is a particularly useful theoretical framework as it makes a fine-grained distinction between different forms of extrinsic motivation. It also helps explain how management and leadership styles and practices may shape the motivation of individuals who start volunteering. Indeed, it allows assessing to what extent volunteers who are initially extrinsically motivated to join the Red Cross may move to a state of more internalised motivation, and how the management approach stimulates this (or not). Finally, this theory has been shown to have good cross-cultural validity and demonstrates that employees who feel autonomous, competent and related to others are more likely to be truly engaged no matter what their background may be. ${ }^{52}$ Indeed, SDT research focuses not on the consequences of the strength of those needs for different individuals, but rather on the consequences of the extent to which individuals are able to satisfy the needs within their social environment. ${ }^{17}$

We also reviewed a number of studies in the field of organisational behaviour ${ }^{57}$ 60-62 to better understand the corresponding short-term and long-term outcomes of management, leadership practices and the influence of organisational context. Globally, such antecedents have an effect on work behaviour, such as task performance, task persistence, attendance and organisational citizenship behaviour, through factors at the level of attitude (intention to quit, job satisfaction, organisational commitment). Work behaviour contributes to organisational performance and individual well-being.

The iterative steps we followed in building the initial PT are summarised in table 2 below.

The overall result of this first step is the formulation of the initial PT, which links the intervention inputs (capacity-building strategies) to the expected outcomes (volunteers' positive work behaviour; figure 3).

This initial PT represents a hypothesis that will be tested empirically in the field study in Uganda:

Management practices and leadership styles (intervention) that are supportive of autonomy lead to positive work behaviour of volunteers, such as improved task performance and persistence (outcomes), because they satisfy the psychological needs of autonomy, competence and relatedness (mechanism). More specifically, such management and leadership contribute to a shift from 'external motivation' towards 'internalised motivation' for the volunteers whose initial engagement was more driven by external motives. Internalised motivation leads not only to positive work behaviour, but also to wellbeing. Such management and leadership furthermore allow volunteers whose initial engagement was mainly driven by internal motives to remain engaged and perform well.

Other conditions for such outcomes to be attained include the organisational context, whereby a good match of the organisational culture and mission with the volunteers' expectations matters, and resource availability (context).

\section{Step 2: Study design}

In realist evaluation, the choice of the design is informed by the PT: the design should allow testing of the different elements of the PT. For the evaluation of the capacity-building intervention, we will use the case study design, ${ }^{63}$ with contrasting cases. We define a case as a RC branch unit, responsible for programme implementation and coordination in one district. Indeed, in order to explore how leadership and management practices shape the motivation and the work behaviour of the volunteers, the case study design is a good choice. Paraphrasing Yin ${ }^{63}$ this design allows a description and assessment of the leadership and management practices in the case-specific context and a link to the workexpected outcomes. Different cases can be analysed and compared, since the PT is the bridge between cases. 
Table 1 Selected theories relevant to volunteer motivation and work behaviour in humanitarian organisations

\begin{tabular}{|c|c|c|}
\hline Theory & Assumptions & Interventions informed by the theory \\
\hline Crowding theory ${ }^{53}$ & $\begin{array}{l}\text { Extrinsic goals coming from outside the self, } \\
\text { including salaries, can crowd out intrinsic } \\
\text { motivation }\end{array}$ & $\begin{array}{l}\text { Appropriate incentives: align context-specific } \\
\text { expectations of community health workers, } \\
\text { programme managers, and policymakers for } \\
\text { low attrition and high performance to be } \\
\text { achieved }\end{array}$ \\
\hline Intrinsic motivation theory ${ }^{54}$ & $\begin{array}{l}\text { People choose humanitarian aid work not } \\
\text { because it provides them with material } \\
\text { extrinsic rewards, but because it creates } \\
\text { immaterial intrinsic rewards }\end{array}$ & $\begin{array}{l}\text { Compensate for humanitarian aid work with } \\
\text { non-financial incentives }\end{array}$ \\
\hline $\mathrm{SDT}^{17-51}$ & $\begin{array}{l}\text { Conditions supporting the individual's } \\
\text { experience of autonomy, competence and } \\
\text { relatedness foster the most volitional and high } \\
\text { quality forms of motivation and engagement } \\
\text { for activities }\end{array}$ & $\begin{array}{l}\text { Match the task to the volunteer's functional } \\
\text { motives } \\
\text { Allow the volunteer to participate in the } \\
\text { development of a programme } \\
\text { Provide supportive supervision } \\
\text { Allow interdependence among employees } \\
\text { and identification with work groups } \\
\text { Provide in-kind rewards, appropriate } \\
\text { material and task support }\end{array}$ \\
\hline $\begin{array}{l}\text { Gift exchange and } \\
\text { high-performance HRM } \\
\text { theory }^{55}\end{array}$ & $\begin{array}{l}\text { Retention and performance will be higher and } \\
\text { turnover lower in organisations with } \\
\text { comparatively high investment in, and care for, } \\
\text { employees }\end{array}$ & $\begin{array}{l}\text { Bundles of incentives } \\
\text { Investment in support }\end{array}$ \\
\hline Consistency theory ${ }^{56}$ & $\begin{array}{l}\text { Practices need to be consistent for high } \\
\text { retention and performance }\end{array}$ & $\begin{array}{l}\text { Internal consistency (among different HRM } \\
\text { practices) } \\
\text { Contextual consistency (between HRM } \\
\text { practices and organisational context) }\end{array}$ \\
\hline $\begin{array}{l}\text { Organisational } \\
\text { commitment }^{57}\end{array}$ & $\begin{array}{l}\text { Organisational commitment contributes to } \\
\text { better job-related attitudes, higher job } \\
\text { satisfaction and better organisational } \\
\text { performance. } \\
\text { The type of organisational commitment that } \\
\text { encompasses accepting the organisational } \\
\text { goals, being committed to the organisation, } \\
\text { and feeling engaged with and attached to the } \\
\text { organisation appears to be facilitated by } \\
\text { autonomous motivation (link with SDT } \\
\text { theories) }\end{array}$ & $\begin{array}{l}\text { Institute practices that facilitate positive } \\
\text { psychological links between organisational and } \\
\text { employee goals }\end{array}$ \\
\hline Social exchange theory ${ }^{58}$ & $\begin{array}{l}\text { HRM practices influence the employees' } \\
\text { perceptions of organisational support, which in } \\
\text { turn induce positive work attitudes and } \\
\text { behaviours based on the norm of reciprocity }\end{array}$ & $\begin{array}{l}\text { Practices such as career development } \\
\text { opportunities, investment in training, etc, signal } \\
\text { the organisation's commitment to the } \\
\text { employees }\end{array}$ \\
\hline The functional approach ${ }^{59}$ & $\begin{array}{l}\text { When volunteers' important motivations for } \\
\text { service are paired with features of the } \\
\text { environment that allow them to actualise these } \\
\text { motivations, then volunteers will be more } \\
\text { satisfied and more likely to continue } \\
\text { volunteering in the future }\end{array}$ & $\begin{array}{l}\text { Appropriate incentives } \\
\text { Match the volunteers' functional motives to } \\
\text { the activities that they are asked to perform }\end{array}$ \\
\hline
\end{tabular}

HRM, Human Resource Management; SDT, self-determination theory.

Case selection

The Uganda RC strengthens routine immunisation in five districts in Kampala. In order to test different elements of the PT, we aim at identifying extreme cases that would present variation in term of managerial practices, organisational context, characteristics of individuals, availability of resources and volunteer behaviour. In practice, we decided to start with two cases in order to contrast the managerial practices and/or the outcomes in terms of volunteer behaviour. We identified two cases in Kampala: Kampala East and Kampala West. The choice of the cases has been made in conjunction with the Uganda Red Cross Society, taking account of different leadership/managerial practices, resources and turnover of volunteers in the two districts. We aim to understand how and why the leadership and managerial 
Table 2 Methods and outputs at each step in building the initial programme theory of the intervention

\begin{tabular}{|c|c|c|c|}
\hline Steps & Question & Methods & Outputs \\
\hline $\begin{array}{l}\text { Eliciting the } \\
\text { programme theory } \\
\text { of the actors }\end{array}$ & $\begin{array}{l}\text { How is the CBH capacity-building } \\
\text { intervention supposed to work? } \\
\text { What were the assumptions of the } \\
\text { implementers? }\end{array}$ & $\begin{array}{l}\text { Interview with RC programme } \\
\text { manager and volunteers. } \\
\text { Review of RC CBH programme } \\
\text { documents and reports }\end{array}$ & $\begin{array}{l}\text { The assumptions of the actors } \\
\text { on the mechanisms through } \\
\text { which they believe the } \\
\text { outcomes are brought about, as } \\
\text { well as the required context } \\
\text { conditions }\end{array}$ \\
\hline Realist synthesis & $\begin{array}{l}\text { What is the evidence on the } \\
\text { effectiveness of community health } \\
\text { volunteer interventions? }\end{array}$ & $\begin{array}{l}\text { Realist review of community } \\
\text { health volunteer programmes }\end{array}$ & $\begin{array}{l}\text { Identification of potential } \\
\text { mechanisms through which the } \\
\text { outcomes are expected to be } \\
\text { brought as well as the required } \\
\text { context condition }\end{array}$ \\
\hline $\begin{array}{l}\text { Identification of } \\
\text { the potential } \\
\text { contextual factors }\end{array}$ & $\begin{array}{l}\text { What are the conditions in } \\
\text { Uganda that may affect RC } \\
\text { volunteers and the expected } \\
\text { outcomes? }\end{array}$ & $\begin{array}{l}\text { Desk review of the Ugandan } \\
\text { context, conversations with } \\
\text { Ugandan RC volunteers, } \\
\text { preliminary surveys of Uganda } \\
\text { RC staff }\end{array}$ & $\begin{array}{l}\text { Potential contextual factors } \\
\text { identified }\end{array}$ \\
\hline $\begin{array}{l}\text { Identification of } \\
\text { potential } \\
\text { mechanisms }\end{array}$ & $\begin{array}{l}\text { Which theories may explain } \\
\text { volunteer positive work } \\
\text { behaviour? }\end{array}$ & $\begin{array}{l}\text { Review of concepts and theories } \\
\text { (management theory, motivation } \\
\text { theory) }\end{array}$ & $\begin{array}{l}\text { Mechanisms and potential MRT } \\
\text { identified }\end{array}$ \\
\hline $\begin{array}{l}\text { Identification of } \\
\text { potential } \\
\text { outcomes }\end{array}$ & $\begin{array}{l}\text { What are the expected outcomes } \\
\text { of managerial and leadership } \\
\text { practices? }\end{array}$ & $\begin{array}{l}\text { Review of studies (organisational } \\
\text { behaviour) }\end{array}$ & $\begin{array}{l}\text { Diverse ranges of outcomes } \\
\text { identified }\end{array}$ \\
\hline $\begin{array}{l}\text { Defining the initial } \\
\text { programme theory }\end{array}$ & $\begin{array}{l}\text { How could the management of } \\
\text { RC community health volunteers } \\
\text { lead to positive work behaviour? }\end{array}$ & $\begin{array}{l}\text { Integration of outputs from the } \\
\text { literature review and desk review } \\
\text { of the Ugandan context into the } \\
\text { programme theory }\end{array}$ & $\begin{array}{l}\text { The initial programme theory } \\
\text { (figure 2) }\end{array}$ \\
\hline
\end{tabular}

practices at branch level could contribute to different outcomes.

\section{Step 3: Data collection tools}

Realist evaluation is method neutral: the choice of data collection methods is determined by the nature of the research questions and the initial $\mathrm{PT}^{42}$ In this study, mixed methods will be used in data collection, including individual interviews, participant observation and document reviews.

We will use a number of data collection tools. To describe the organisational context, we will develop a typology of context tool that will focus on the work design and organisational context. We will first review
Figure 3 Community health volunteers' work behaviour: links between strategies and outcomes.

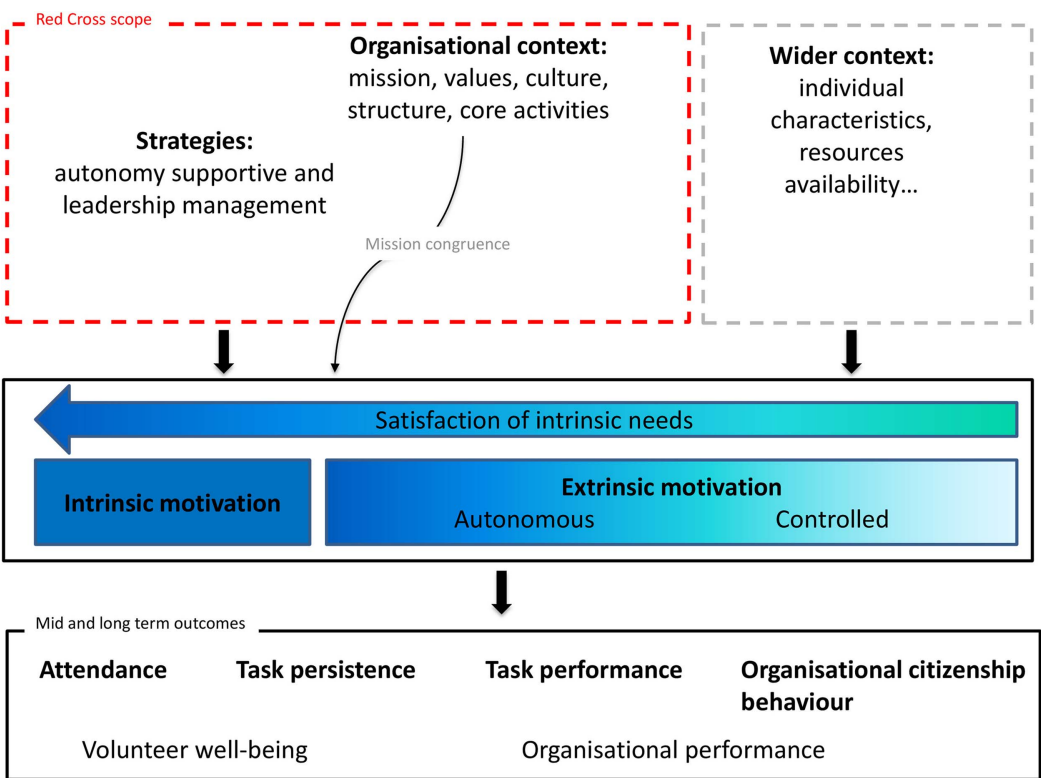


Uganda Red Cross documents (eg, policies, reports, legal frameworks, codes of conduct), conduct a survey among staff members of the $\mathrm{RC}$ volunteering department in the Geneva IFRC headquarters and have meetings with Uganda RC staff. Questions will focus on organisational structure, recruitment practices, community health and first aid activities, the organisation of immunisation campaigns, financing, challenges volunteers are facing and challenges managers are facing with managing volunteers. This will contribute to building a picture of the RC organisational context in Uganda.

In the two cases (Kampala East and Kampala West), we will perform in-depth individual interviews with volunteers. While RC volunteers' profiles in Kampala vary, they are largely characterised by being young, welleducated and mostly unemployed. Men and women are equally represented. Some volunteers are very active and others are passive (they come only for a specific programme or when they have time), some are community volunteers and others are leader volunteers. The experience of the volunteers with the $\mathrm{RC}$ varies from a few months to more than 40 years. The selection of the interviewees in each case is largely purposive. To enable exploration of the influence of context and leadership and management practices on a variety of individual volunteers, we will aim for diverse profiles. Theoretical sampling involves participants with different experiences of the phenomenon so as to expose multiple facets of the phenomenon. Interviews will be conducted until theoretical saturation is reached. ${ }^{64}$ We expect to reach saturation with the interview of 13 volunteers per site (see table 3 for an overview of respondents). However, this number is flexible and will depend on the level of saturation obtained.

Respondents will be invited to participate voluntarily in the study and will receive a small allowance in line

\begin{tabular}{|c|c|}
\hline Volunteer respondents & $\begin{array}{l}\text { Number of } \\
\text { interviews per site }\end{array}$ \\
\hline Leaders & 2 \\
\hline $\begin{array}{l}\text { Chairperson (Branch governing } \\
\text { board) }\end{array}$ & 1 \\
\hline \multicolumn{2}{|l|}{ Active volunteers: } \\
\hline Men & $3-4$ \\
\hline Women & $3-4$ \\
\hline Young (from 16 to 30 years old) & 5 \\
\hline Unemployed & $5-6$ \\
\hline Year(s) of experience with the & $3-4$ \\
\hline \multicolumn{2}{|l|}{ Red Cross: 5 years or more } \\
\hline Year(s) of experience with the & 2 \\
\hline \multicolumn{2}{|l|}{ Red Cross: 1 year or less } \\
\hline Total active volunteers & $7-8$ \\
\hline \multicolumn{2}{|l|}{ Non-active volunteers } \\
\hline Men & $1-2$ \\
\hline Women & $1-2$ \\
\hline Total non-active volunteers & 3 \\
\hline
\end{tabular}

with the Uganda RC volunteering policy. We will use a semistructured interview guide for volunteers with open questions (Annex 2) to conduct the interviews. To help acquire certain types of information or to help the respondent, probes will be prepared in advance and used when needed. To understand how RC practices and organisational context shape the motivation and organisational behaviour of the volunteers, the questions will be developed around the following key themes:

- Mechanisms or motivational drivers that contribute to volunteer motivation: volunteer expectations when joining the organisation, benefits they receive from volunteering and reasons for assisting in RC volunteering activities, etc.

- Contextual factors: volunteer work design (tasks to perform, skills to use, etc), the organisational context (interpersonal relations, organisational culture, task distribution, etc).

To document the actual leadership style and management practices, we will, in each district:

- Observe the programme managers in their daily practice;

- Use a questionnaire, adapted from the Problems at Work Questionnaire of Deci $e t a l^{65}$ and directed to the RC programme manager;

- Organise meetings in the two branches, such as community visits, meetings with local leaders, RC youth club, beneficiaries, formal parish health workers, etc;

- Observe volunteers in situ (work practices and relationships with their programme manager, community and partners).

The study does not intend to assess the effectiveness of the capacity building intervention, but rather to understand the link between the intervention and its expected outcomes. To this end, we will identify relevant indicators in order to collect information on the volunteer work behaviour (job performance, task persistence, attendance and organisational citizenship behaviour).

The main spoken languages in Kampala are English and Luganda. The programmes managers of the Uganda RC speak fluent English but some community volunteers may not. Therefore, we will require the assistance of translators during the in-depth interviews. All interviews will be recorded and transcribed verbatim if the respondent agrees with this. We anticipate that using translators may impose a barrier during the interviews, but excluding the non-English speaking volunteers would mean excluding an important and common profile of volunteers.

\section{Step 4: Data analysis}

We will use the constant comparative analysis originally developed by Strauss ${ }^{66}$ in the context of Grounded Theory research. Constant comparative analysis has been used for qualitative research, such as research based on a theoretical framework. ${ }^{67}$ The analysis will help in finding patterns and commonalities within individual experience whereas our PT will be used as a tool 
for identifying and comparing emerging themes. Furthermore, drawing on Ragin's recommendations on comparative case study research: each case will first be examined as a whole and the two cases will then be compared with each other. ${ }^{68}$

As already mentioned, realist evaluation provides the $\mathrm{CMO}$ configuration as a heuristic to analyse data. We will focus on exploring the relationship between the capacity-building strategies, the observed outcomes and the contextual factors (in terms of work design, organisational culture, management style, etc) that may play a role in triggering the mechanisms (starting with, but not limited to, drivers of motivation). The PT provides a frame of analysis, and in line with realist analysis principles, we will aim at identifying and testing CMO configurations.

In practice, the following questions will guide the first round of analysis:

- What motivated the volunteers to join the Red Cross?

- What are the capacity-building strategies implemented by the Red Cross?

- What are the observed outcomes of the capacitybuilding strategies implemented by the Red Cross?

- Can the observed outcomes be linked to the capacitybuilding strategies?

In a second round, we will seek to assess the contribution of the RC management strategies to the observed outcome. Guiding questions include:

- How can the link between the intervention and results be explained? What mechanisms drove the actors to make decisions in the light of the programme?

- Which context conditions facilitated these decisions? Which conditions are essential?

- Are there alternative explanations (ie, other interventions that took place)?

In a third round, the analysis focuses on identifying potential patterns, whereby outcomes are linked to intervention through mechanisms that were triggered for specific actors in a specific context. The resulting CMO configurations are then assessed to see whether they hold as plausible patterns (in realist evaluation also called 'demi-regularities') that explain how the intervention brought about the observed results. We will complete findings by combining the different data sources (observation notes, interviews and secondary document analysis) to confirm or reject initial findings and themes. The results will be a (set of) CMO configuration(s) that provide plausible explanations for the observed outcomes and that are backed up by empirical data.

\section{Step 5: Synthesis}

In the last step of each case study, we will relate the retained CMO configurations to the initial PT and accept, modify or reject its clauses in order to formulate a plausible explanation of how and why specific strategies for implementation of community-based intervention involving volunteers bring about better work behaviour among volunteers.

After finalising in-case analysis, we will carry out a cross-case analysis of the results: the results of each case, in the form of the refined PT, will be compared, taking into account the differences or similarities in outcomes on volunteers' behaviour and organisational context level. This is expected to lead to a better understanding and to plausible explanations of how interactions between actors, leadership, managerial practices and organisational context influence volunteer motivation and work behaviour.

\section{Ethics}

In this section, we describe how ethical issues were identified and which measures will be taken. Our ethical considerations are based on the working paper "Notes regarding ethical guidelines for health services research", prepared for the Departmental Council of the Department of Public Health, Institute of Tropical Medicine, Antwerp.

\section{Identification of ethical issues}

Being identified as participating in this study carries the risk that expressing unfavourable opinions of management team may lead to negative actions of the latter at a later stage. This protocol spells out several measures to keep the risk of identification of interviewees and attribution of findings to them as low as possible.

- The selection of interviewees will be carried out without involvement of the branch manager as far as possible.

- The invitations will be sent in a non-conspicuous manner.

- Interviews will be carried out in a space that is most convenient for the respondent.

- All interviews, their recordings and related notes will be given individual identifiers, and the list of respondents and their identifiers will be kept separately from the data.

- At all stages of the study, data will be kept strictly confidential.

- Findings will be reported anonymously and will not be attributed to any participant.

In practice, absolute anonymity (or keeping the identity of participants known only to evaluation team members) may prove impossible. These modalities will be discussed with all potential interviewees at the start and described in the invitation letter and in the informed consent form.

\section{Measures: invitation, information and informed consent}

The study proposal was shared with Uganda RC and a formal agreement was signed by the Secretary General of Uganda RC.

The study will be presented to the staff of the Uganda RC. The aims and objectives of the study will be explained and opportunities for questions will be provided. 
All participants, such as Uganda RC staff, RC volunteers and stakeholders, will be invited and informed of the study through formal correspondence (even when they may be involved in informal discussions).

The consent form will be written in English and include a section on the potential risks and benefit of the study to the participant and/or to the National Society. However, when needed, it will be orally translated at the beginning of the interview. Before the interview, sufficient time will be dedicated to oral explanation of the content and to answer any questions the interviewee might have. More specifically, we will use this time to discuss the potential impact of the study findings: discovering poor practices will not lead to sanction of the volunteers or programme manager in Uganda, but will contribute to the improvement of the RC managerial practices in general. Second, better knowing what to improve regarding Uganda RC managerial practices in their context may provide a rationale for donors to invest further in capacity-building interventions for volunteers.

The interview schedule will be prepared by volunteers at branch level at a suitable and convenient time for respondents. The appointment for interview will be notified in advance. The location will be determined by the participant (eg, home, workplace, RC office).

Participants will have the option to decline participation in the study. The RC volunteers will be informed that non-participation in the study will not affect their further work in the immunisation programme under study nor in any other activity of the Uganda RC. Written consent will be sought for each respondent. Approval for audio recording of interviews shall be sought in addition to the consent for taking notes of the interview.

Opportunities for feedback of findings will be explored, and may include a feedback session with the branch manager as well as the volunteers (if practically feasible during the field study). A copy of the final evaluation report will be sent to the national headquarters of the Uganda RC.

\section{Quality control}

First, to increase validity of our data, field notes will be compared and discussed between the two investigators in Uganda and put together in one document. We also designed a method to spot-check the transcriptions and determine their quality. All the data from the qualitative data collection methods will be organised on Excel software with clear documentation of the procedures adopted and consistent file-naming. Analysis of the interview transcripts, categorisation and analysis will be crosschecked by three researchers.

\section{DISCUSSION}

In this study of the RC CBH capacity-building intervention in two districts in Uganda, we aim to explore and better understand the motivation of RC volunteers.
The initial PT will be tested and the resulting refined pathway may provide useful information to be used by programme implementers, policymakers, donors and the community. It may also guide the design of interventions involving volunteers and help to improve their performance.

We encountered several challenges to build our initial PT, some of them already identified by Marchal et $a \tilde{l}^{0}$ in a review of realist evaluations in health systems research. In search for guidance on mechanisms, we found that authors differ on the way they conceptualise mechanisms, and diverging views exist regarding the difference between mechanisms and essential context conditions. Furthermore, the choice of relevant theory to inform the development of the initial PT required quite some work and was a challenging task: realist evaluations benefit from working in multidisciplinary teams.

Owing to the lack of clear definitions within the literature, we faced some difficulties in our search for potential mechanisms. In order to keep the explanatory power of mechanisms, ${ }^{69}$ which is in our view one of the main strengths of the realist approach, we searched for psychological or social explanations of volunteer motivation and positive work behaviour. We considered that mechanisms are not the resources or tangibles offered by an intervention (intervention inputs), nor modalities of the intervention. Rather we defined mechanisms as the psychological or social explanations for volunteers' choice and behaviour, in which the interaction between the volunteers and key stakeholders (group level) and between the volunteers and organisational factors (incentives or constraints that shape volunteers' motivation and work behaviour) play a role.

From a realist evaluation perspective, context comprises the individual capabilities of key actors, the interpersonal relationships supporting the intervention, the institutional setting and the wider contexts that occur independently of the intervention and may affect the implementation of the intervention, the choices of the participants and/or the outcomes. During step 1, when we built up the initial PT, we faced some challenges to identify potentially important context factors. First, the main outcomes documented in papers related to community health volunteer performance are health outcomes of beneficiaries. If the context factors are discussed, authors focus on factors that have an influence on these health outcomes and not on health volunteer behaviour. Second, a component of an intervention can itself have an influence on the other components of the intervention and on the expected outcomes. Should such a component then be considered as a context factor? Moreover, the initial effects of an intervention (not always identifiable) can become contextual factors at a later stage, which can influence the expected outcomes. In response, we decided that two researchers would review the literature in order to identify the wide range of potential context factors. This step was followed by discussion of the role of contentious factors. 
Our literature review identified a large number of theories that somehow apply to motivation of employees or staff working in public organisations and it was difficult to decide which theory would be most useful to study volunteer motivation. We explained above our choice for SDT (section Step 1: Formulating the PT). We will also remain open to the possibility that other theories, such as functional theory or social exchange theories, might help explain emerging findings.

Finally, this study could benefit from measuring volunteers' autonomous motivation and intrinsic motivation in the two branches. This would allow us to validate or refine the initial PT more robustly. While some of the scales, such as the Multidimensional Work Motivation Scale,$^{52}$ have been tested in a large number of countries, there is little documentation of validation studies of such tools in developing countries and the applicability of such scales may be challenging.

\section{Author affiliations}

${ }^{1}$ EHESP Rennes, Sorbonne Paris Cité, Rennes, France

${ }^{2}$ CNRS, UMR CRAPE Centre de Recherches sur l'Action Politique en Europe6051, Rennes, France

${ }^{3}$ Department of Development, Policy and Practice, Royal Tropical Institute,

Amsterdam, The Netherlands

${ }^{4}$ International Federation of Red Cross and Red Crescent Societies,

Community Health and Innovation, Geneva, Switzerland

${ }^{5}$ Department of Public Health, Institute of Tropical Medicine, Antwerp, Belgium

Acknowledgements The authors wish to first thank the Uganda Red Cross for welcoming the study and facilitating it. They would like also to acknowledge the inputs of the IFRC Community Health and Innovation unit and the IFRC volunteering department especially Ayham Alomari and Shaun Hazeldine. They are grateful for the work of Taja Petric, Christina Velez and Judith Jaschick (Master Students, the Graduated Institute of Geneva) for performing the interviews aiming at eliciting Red Cross stakeholder assumptions regarding the $\mathrm{CBH}$ programme. The authors thank Red Cross volunteers and programme managers from Sierra Leone, Argentina, the Philippines and Burundi for their participation. They also thank Vivienne Seabright (Consultant, IFRC) for English language editing of the manuscript. Finally, they would like to thank more specifically Taja Petric for support provided.

Contributors All the authors contributed to conceptualise the study and to develop the tools, with leadership from GV and BM. GV wrote the first draft of the present manuscript. All authors reviewed and provided comments to improve the manuscript. All authors read and approved the final manuscript.

Funding The study is funded by the International Federation of Red Cross and Red Crescent Societies (Geneva, Switzerland). GV is the recipient of a $\mathrm{PhD}$ grant under the IFRC funding that provides a monthly stipend and a bench fee to cover local travel and research expenses.

Competing interests None.

Ethics approval Ethical approval was provided by the Ethical Committee at Rennes University Hospital, France (CHU Rennes Hotel Dieu-Rennes, France-Approval number 14.41).

Provenance and peer review Not commissioned; externally peer reviewed.

Data sharing statement No additional data available.

Open Access This is an Open Access article distributed in accordance with the Creative Commons Attribution Non Commercial (CC BY-NC 4.0) license, which permits others to distribute, remix, adapt, build upon this work noncommercially, and license their derivative works on different terms, provided the original work is properly cited and the use is non-commercial. See: http:// creativecommons.org/licenses/by-nc/4.0/

\section{REFERENCES}

1. Sein UT. Health Volunteers: Third Workforce for Health-for-AI Movement. Reg Health Forum 2006;10:38-48.

2. Lehmann U, Sander D. Community health workers: what do we know about them? The state of the evidence on programmes activities, costs and impact on health outcomes of using community health workers. Geneva, Switzerland: WHO, 2007.

3. Haines A, Sanders D, Lehmann U, et al. Achieving child survival goals: potential contribution of community health workers. Lancet 2007;369:2121-31.

4. Lewin S, Munabi-Babigumira S, Glenton C, et al. Lay health workers in primary and community health care for maternal and child health and the management of infectious diseases. Cochrane Database Syst Rev 2010;(3):CD004015.

5. Lassi ZS, Haider BA, Bhutta ZA. Community-based intervention packages for reducing maternal morbidity and mortality and improving neonatal outcomes. Cochrane Database Syst 2010;11:CD007754.

6. Wouters E, Van Damme W, Van Rensburg D, et al. Impact of community-based support services on antiretroviral treatment programme delivery and outcomes in resource-limited countries: a synthetic review. BMC Health Services Res 2012;12:194. http:// www.ncbi.nlm.nih.gov/pubmed/22776682 (accessed 21 Aug 2014).

7. Callagan MK, Ford N, Schneider H. A systematic review of taskshifting for HIV treatment and care in Africa. Hum Resour Health 2010;8:8. http://www.human-resources-health.com/content/8/1/8 (accessed 21 Aug 2014).

8. Zacharia R, Ford N, Philips M, et al. Task shifting in HIV/AIDS: opportunities, challenges and proposed actions for sub-Saharan Africa. Trans R Soc Trop Med Hyg 2009;103:549-58.

9. Hermann K, Van Damme W, Pariyo GW, et al. Community health workers for ART in sub-Saharan Africa: learning from experiencecapitalizing on new opportunities. Hum Resour Health 2009;7:31. http://www.human-resources-health.com/content/7/1/31 (accessed 21 Aug 2014)

10. Celletti F, Wright A, Palen J, et al. Can the deployment of community health workers for the delivery of HIV services represent an effective and sustainable response to health workforce shortages? Results of a multicountry study. AIDS 2010;24(Suppl 1): S45-57.

11. Jackson SF, Perkins F, Khandor E, et al. Integrated health promotion strategies: a contribution to tackling current and future health challenges. Health Promot Int 2006;21(Supp1):75-83.

12. Bhattacharyya K, Winch $\mathrm{P}$, LeBan $\mathrm{K}$, et al. Community health worker incentives and disincentives: how they affect motivation, retention and sustainability. Arlington, Virginia: BASICS/USAID, 2001.

13. Nkonki L, Cliff J, Sanders D. Lay health worker attrition: important but often ignored. Bull World Health Organ 2011;89:919-23.

14. McElroy JC, Morrow PC, Rude SN. Turnover and organizational performance: a comparative analysis of the effects of voluntary, involuntary, and reduction-in-force turn-over. J Appl Psychol 2001;86:1294-9.

15. Casiday R, Fisher C, Bambra C, et al. Volunteering and health: what impact does it really have? Report to volunteering England. Volunteering England, 2008.

16. Wang JW, Wei C, Harada K, et al. Applying the social cognitive perspective to volunteer intention in China: the mediating roles of self-efficacy and motivation. Health Promot Int 2011;26:177-87.

17. Gagne M, Deci EL. Self-determination theory and work motivation. J Organiz Behav 2005;26:331-62.

18. Van Schie S, Guntert ST, Oostlander J, et al. How the organizational context impacts volunteers: a differentiated perspective on self-determined motivation. Int Soc Third Sector Res 2014. Advanced Online Publication. doi:10.1007/s11266-014-9472-z

19. Perry JL, Hondeghem A, Wise L. Revisiting the Motivational Bases of Public Service: Twenty Years of Research and an Agenda for the Future. Public Adm Rev 2010;70:681-90.

20. Le Grand J. Motivation, agency and public policy of Knights and Knaves, Pawns and Queens. Oxford: Oxford University press, 2003.

21. Wise LR . Bureaucratic posture: on the need for a composite theory of bureaucratic behavior. Public Adm Rev 2004;64:669-80.

22. Frymus D, Kok M, De Koning K, et al. Knowledge gaps and a need based Global Research agenda by 2015. Working paper. Geneva, Switzerland: the Global Health Workforce Alliance, 2013. http://www. who.int/workforcealliance/knowledge/resources/CHWsResearch Agenda_by2015.pdf (accessed 16 Sep 2014).

23. Burton P, Goodlad R, Croft J. How would we know what works? Context and complexity in the evaluation of community involvement. Evaluation 2006;12:294-312.

24. Amizaki Y, Hu T, Li S, et al. Country briefing: Uganda-Health Global Health at MIT. 2011. https://globalhealth Hu,.mit.edu/ uganda-health/ (accessed 16 Sep 2014) 
25. The World Bank. Uganda at a glance. http://devdata.worldbank.org/ AAG/uga_aag.pdf (accessed 16 Sep 2014).

26. United Nations, Department of Economic and Social Affairs. World population prospects: the 2012 revision. http://esa.un.org/unpd/wpp/ Excel-Data/population.htm (accessed 16 Sep 2014).

27. Natukunda C. Uganda Population at Record 37 Million. New visionUganda's Leading Daily. 23 Jun 2013. http://www.newvision.co.ug/ news/644270-uganda-population-at-record-37-million.html (accessed 16 Sep 2014).

28. Uganda Bureau of statistics. 2011 mid-year projected population for town council. http://www.ubos.org/onlinefiles/uploads/ubos/pdf\% 20documents/TP52010.pdf (accessed 16 Sep 2014).

29. Ogwang J . Slums present a fierce challenge to Uganda's urbanisation effort. New vision-Uganda's Leading Daily. 13 March 2013. http:// www.newvision.co.ug/news/640621-slums-present-a-fierce-challengeto-uganda-s-urbanisation-effort.html (accessed 16 Sep 2014).

30. Nabiruma D. Uganda worst in immunisation in Eastern and Southern Africa. The observer. 30 April 2013. http://observer.ug/index.php? option=com_content\&view=article\&id=24994:-uganda-worst-in immunisation-in-eastern-and-southern-africa\&catid=58:healthliving\&ltemid=89 (accessed 16 Sep 2014).

31. The Republic of Uganda. Uganda National Expanded Programme on Immunization Multi Year Plan 2012-2016 Update Multi Year Plan 2013. World Health Organisation/UNICEF, 2013. http://www. nationalplanningcycles.org/sites/default/files/country_docs/Uganda/ uganda_epi_cmyp 2012-2016.pdf (accessed 16 Sep 2014).

32. Craig P, Dieppe P, Macintyre S, et al. Medical Research Council Guidance. Developing and evaluating complex interventions: the new Medical Research Council Guidance. BMJ 2008;337:a1655

33. Rogers PJ. Implications of complicated and complex characteristics for key tasks in evaluation. In: Forss K, Marra M, Schwartz R. eds. Evaluating the complex: attribution, contribution, and beyond. New Brunswick: Transaction Publishers, 2011;18:33-52.

34. Pawson R, Greenhalgh T, Harvey G, et al. Realist review-a new method of systematic review designed for complex policy interventions. J Health Serv Res Policy 2005;10(Suppl 1):21-34.

35. Rowe AK, de Savigny D, Lanata CF, et al. How can we achieve and maintain high-quality performance of health workers in low-resource settings? Lancet 2005;366:1026-35.

36. Sterman JD. Learning from evidence in a complex world. $A m \mathrm{~J}$ Public Health 2006;96:505-14.

37. Fulop N, Allen P, Clarke A, et al. Studying the Organisation and Delivery of Health Services: Research Methods. London: Routledge, 2001.

38. Berwick DM. The science of improvement. JAMA 2008;299:1182-4.

39. Stern E, Stame N, Mayne J, et al. Broadening the range of designs and methods for impact evaluations. Department for International Development. Report, 2012.

40. Westhorp G. Using complexity-consistent theory for evaluating complex systems. Evaluation 2012;18:405-20.

41. Marchal B, Van Belle S, De Brouwere V, et al. Studying complex interventions: reflections from the FEMHealth project on evaluating fee exemption policies in West Africa and Morocco. BMC Health Serv Res 2013;13:469.

42. Pawson R, Tilley N. Realistic evaluation. London: Sage Publication, 1997.

43. Pawson R. Evidence-based policy. A realist perspective. London: Sage Publications, 2006.

44. Pawson R, Tilley N. Realist evaluation. In: DPRN Thematic Meeting 2006 Report on Evaluation. The Netherland: Development Policy Review Network, 2008

45. Mingers J. The contribution of critical realism as an underpinning philosophy for OR/MS and systems. J Oper Res Soc 2000;51:1256-70.
46. Marchal B, Dedzo M, Kegels G. A realist evaluation of the management of a well-performing regional hospital in Ghana. BMC Health Serv Res 2010;10:24. http://www.biomedcentral.com/14726963/10/24 (accessed 16 Sep 2014)

47. Manzano-Santaella A. A realistic evaluation of fines for hospital discharges: incorporating the history of programme evaluations in the analysis. Evaluation 2011;17:21-36.

48. Blaise P, Kegels G. A realistic approach to the evaluation of the quality management movement in health care systems: a comparison between European and African contexts based on Mintzberg's organizational models. Int $J$ Health Plann Manage 2004:19:337-64.

49. Pedersen $\mathrm{L}$, Rieper $\mathrm{O}$. Is realist evaluation a realistic approach for complex reforms? Evaluation 2008;14:271-93

50. Marchal B, Van Belle S, Van Olmen J, et al. Is realist evaluation keeping its promise? A literature review of methodological practice in health systems research. Evaluation 2012;18:192-212.

51. Deci EL, Ryan RM. Intrinsic motivation and self-determination in human behaviour. New York: plenum, 1985

52. Gagné M, Forest J, Vansteenkiste M, et al. The Multidimensiona Work Motivation Scale: validation evidence in seven languages and nine countries. Eur J Work Organ Psychol 2014. http://dx.doi.org/10.1080/1359432X.2013.877892 (accessed 23 Jan 2015)

53. Frey BS, Jegen R. Motivation crowding theory: a survey of empirical evidence. J Econ Surv 2001;15:589-611.

54. White RW. Motivation reconsidered: the concept of competence. Psychol Rev 1959;66:297-333.

55. Cheal DJ. The gift economy. New York: Routledge, 1988:1-19.

56. Festinger L. $A$ theory of cognitive dissonance. Stanford, CA: Stanford University Press, 1957.

57. Meyer JP, Allen NJ. A three-component conceptualization of organizational commitment. Hum Resour Manag Rev 1991;1:61-89.

58. Emerson R. Social exchange theory. Annu Rev Sociol 1976;2:335-62.

59. Clary EG, Snyder M, Ridge R, et al. Understanding and assessing the motivations of volunteers: a functional approach. J Pers Soc Psychol 1998;74:1516-30.

60. Podsakoff PM, Mackenzie SB, Beth Paine J, et al. Organisational citizenship behaviours: a critical review of the theoretical and empirical literature and suggestions for future research. $J$ Manage 2000;26:513-63.

61. Cropanzano R, Mitchell M. Social exchange theory: an interdisciplinary review. J Manage 2005;31:874-900.

62. Settoon RP, Bennett N, Liden RC. Social exchange in organizations: perceived organisational support, leader-member exchange and employee reciprocity. J Appl Psychol 1996:81:219-27.

63. Yin RK. Case study research: design and methods. 2nd edn. Thousand Oaks: Sage, 1994

64. Corbin J, Strauss A. Basics of qualitative research: techniques to developing grounded theory. 3rd edn. Los Angeles, CA: Sage, 2008.

65. Deci EL, Connell JE, Ryan RM. Self-determination in a work organization. J Appl Psychol 1989;74:580-90.

66. Strauss AL. Qualitative analysis for social scientists. New York: Cambridge University Press, 1987.

67. Fram SM. The constant comparative analysis method outside of grounded theory. Qual Rep 2013:18:1-25.

68. Ragin CC. The comparative method: moving beyond qualitative and quantitative strategies. Berkeley: University of California Press, 1987.

69. Pawson R. Invisible mechanisms. Eval J Australasia 2008;8:3-13. 